\title{
The influence of references per paper in the SCI to Impact Factors and the Matthew Effect
}

\author{
Mohammad Hossein Biglu \\ Mh_biglu@yahoo.com
}

\begin{abstract}
:
All references data was extracted from the annual volumes of the CD-Edition of Science Citation Index (SCI) and the web of science of the Institute for Scientific Information (ISI), the journal citation and self-citation data extracted from the journal Citation Report (JCR), the self-citing rate and self-cited rate calculated based on the JCR method.

To determine the trend of mean value of references per paper throughout 1970-2005, a total number of 10,000 records were randomly chosen for each year of under study, and the mean value of references per paper was calculated...

To determine the growth of journals IF a total number of 5,499 journals were chosen in the JCR in 2002 and the same set of journals in the year 2004.

To show the trend of journals IF, all journals indexed in the JCR throughout 1999-2005 were extracted and the mean values of their IFs was calculated annually.

The study showed that the number of references per paper from 1970 to 2005 has steady increased. It reached from 8.40 in 1970 to 34.63 in 2005, an increase of more than 4 times.

The most majority of publications (76.17\%) were in the form of Journals article, after articles, Meeting abstract with $9.46 \%$, Note with $3.90 \%$ and Editorial material with $3.78 \%$ are respectively the most frequented publication forms.

94.57\% of all publications were in English. After English German with 1.50\%, Russian with $1.48 \%$ and French with $1.37 \%$ were respectively the most frequented languages.
\end{abstract}

The study furthermore showed that there is a significant correlation between the IF and total citation of journals in the JCR, and there is an important hidden correlation between IF and the self-citation of journals. This phenomena causes the elevation of journals IF.

As more often a journal is citing other journal as more often it is also cited by a factor of 1.5 from others. In consequence the growing percentage of journal self citation is followed by journal self citedness, which can be considered as The Matthew Effect.

There is a linear correlation between journal self-citing and journal self-cited value, the mean value of self-cited rate always stays higher than the self-citing rate.

The mean value of self-cited rate in 2000 was $14 \%$ and the mean value of self-citing rate is $6.61 \%$, whereas the mean value of self-cited rate in 2005 was $12 \%$ and the mean value of selfciting rate was $7.81 \%$.

Introduction:

The nearly constant growth of scientific literature with a doubling rate of 20 years since 350 years in the scholarly world lead to growing difficulties in libraries to offer all these publications to their patrons. Easier access could be reached in the last years with electronic journals and the digitalisation of books. Such offers in the Internet made it also possible to cite more references in the works. On the other hand attempts to get high prestige among academic scientists and researchers may be one of other reasons that increased the citation 
rate. Such an elevation of references per paper was registered by E. Garfield in 1980. In his study based on his SCI data base (2), he showed that the average biochemistry article contained at least $70 \%$ more references than the average article in the SCI data base. He asserted that some CEBJ-journals (Committee of Editors of Biochemical Journals) have increased their average number of references per source item by as much as $64 \%$ in 16 years. In this comparison biochemistry references were roughly $80 \%$ higher than SCI journals. In this study Garfield raised the question "why should current authors generally cite more references than they did in the past" and his assumptions are that there are five possible reasons.

1. "The first concerns the increase in team research. Since the reward system of science places so much stress on 'first' authorship, this encourages research teams to publish multi-part papers that could just as easily be published as one paper."

2. "A second reason for an increase in the average number of references per paper is the growth of the literature itself. Price argues that part of this increased citation is the inevitable by-product of exponential growth. If the size of the literature that can be cited increases, there is an increase in average citation. This may be true in the early phases of growth, but ultimately there must be a levelling off or all papers will become reviews!"

3. "A third reason may also be related to the SCI and what I call citation consciousness. It comes from the realization that to cite another person's work is to increase the number of times your own work appears in the Citation Index, which increases the possibility other people will have contact with it."

4. "A fourth likely reason is the general improvement in the average author's awareness of newly published material because of improved 'current awareness' systems."

5. "A related fifth possible explanation is that researchers have become more aware of the SCI and other indexing and abstracting tools and thereby have improved their retrospective search capability."(4)

Especially the last point can be seen today in relation to the pursuit of higher Impact Factors, and a systematic utilization of the Matthew Effect.

The fourth point is not so plausible, if we consider the problems of libraries in the last century to make all running journals and other sources available, and the advent of Internet or the Open Access Initiative has not triggered a quantum leap in this development.

The "citation consciousness" of the third point finds its root in the publish-or-perish principle and the discovery, that publications in journals are only high-ranking if the IF is extraordinary.

In Garfield's first suggestion, most probable the growing number of references per paper is also a consequence of multiple authorship because journal self citation is growing proportional to the number of references per paper.

As Garfield observed with "more references in biochemistry articles, the references are to a higher proportion of older material than was the case previously." From 1969 to 1977, the percentage of cited papers older than 5 years increased from $46 \%$ to $53 \%$ for 18 of the biochemical core journals. This would be a hint that the IF are influenced only slightly, because the citations are counted from the last two years.(footnote 2)

In other study Fassoulaki A, et al. found that self-citation of journals is an important factor. They investigated self-citations in the 1995 and 1996 issues of six anaesthesia journals by calculating the self-citing and self-cited rates for each journal. They found A significant 
correlation between self-citing rates and Impact Factors ( $\mathrm{r}=0.899, \mathrm{P}=0.015)$. Their study indicated that a high self-citing rate of a journal may positively affect its Impact Factor. (1)

In this context it is important to recognize the portion of journal self citation. In self citation we have to distinguish between author self-citation, if an author cites his or her previous works, self-citation of different authors in collaborative works, institutional self-citation, selfcitation of "invisible colleges"(10), and journal self-citations.

We are interested here in journal self-citations, their Influence to the Impact Factor and its influence to the Matthew Effect. In science, Matthew Effect is a term coined by Robert K. Merton to describe how, among other things, eminent scientists will often get more credit than a comparatively unknown researcher even if their work is similar; it also means that credit will usually be given to researchers that are already famous. That means also, that the papers of an author are more often cited if the author is well known (9). This is the cause that journals try to get higher and higher IF to get more credit.

Journal self-citation may be defined in two ways: 1.The proportion of a journal's references that are to itself; 2.The percentage of citations recorded by a journal that drive from itself.

Methodology:

Bearing this hypothesis in mind that there is an association between the journal self-citations, the Impact Factor, and their influence to the Matthew Effect, all references data was extracted from the annual volumes of the CD-Edition of the SCI and the web of science of the Institute for Scientific Information (ISI), the journal citation and self-citation data extracted from the JCR, the self-citing rate and self-cited rate calculated based on the JCR method.

To determine the trend of mean value of references per paper throughout 1970-2005, a total number of 10,000 records were randomly chosen for each year of under study, and the mean value of references per paper was calculated...

To show the difference of journals IF, a total number of 5,499 journals indexed in the JCR in 2002 and the same set of journals in 2004 were extracted from the JCR, and the difference of their IFs was calculated.

To determine the trend of self-citation of journals, a total number of 500 journals were randomly chosen in 2000 and the same set of journals in 2005 from the JCR. If a journal was published in the year 2000 and it was not found in 2005 or it was published in 2005 but such journal was not found in 2000 (its publishing date was after 2000), an alternative journal which was published both in 2000 and 2005 was selected.

\section{Findings:}

If we look in the SCI from 1970 to 2005 in randomised samples of 10,000 records for the number of references, we see a clear multiplication of references per paper (Table 1)

Table 1:

Mean value of references per paper from 1970 to 2005

\begin{tabular}{|l|l|l|l|}
\hline Years & No. of records & $\begin{array}{l}\text { No. of references for } \\
\text { randomized chosen } \\
\text { records }\end{array}$ & $\begin{array}{l}\text { Mean value of } \\
\text { references per } \\
\text { paper }\end{array}$ \\
\hline
\end{tabular}




\begin{tabular}{|l|l|l|l|}
\hline 1970 & 10,000 & 84,045 & 8,40 \\
\hline 1975 & 10,000 & 106,858 & 10,68 \\
\hline 1980 & 10,000 & 150,194 & 15,01 \\
\hline 1985 & 10,000 & 161,389 & 16,13 \\
\hline 1990 & 10,000 & 215,993 & 21,59 \\
\hline 1995 & 10,000 & 287,330 & 28,73 \\
\hline 2000 & 10,000 & 319,074 & 31,90 \\
\hline 2005 & 10,000 & 346,320 & 34,63 \\
\hline
\end{tabular}

As the table 1 indicates, the number of references par paper in 2005 is $412 \%$ higher than the number of references per paper in 1970. A total number of 10,000 documents for each year of study was chosen in the SCI. the number of references per paper were plotted in the table 1.

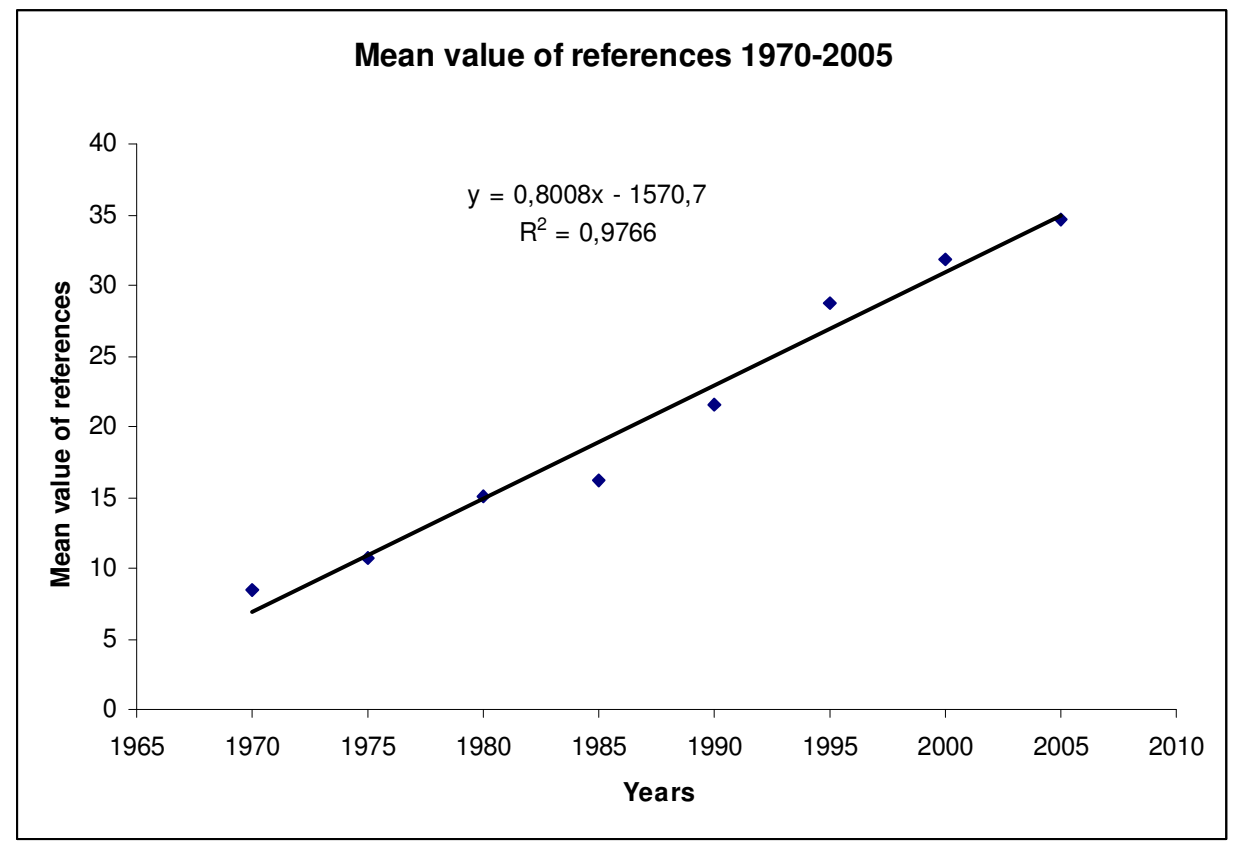

Fig.1: Increase of references per paper from 1970 to 2005 in SCI

The number of references per paper for randomly chosen documents in the SCI, are plotted in Figure 1 for the last 35 years. They show a steady increase with more than four times higher value in 2005 in relation to 1970 .With other words; the number of references per paper in the SCI is growing by 4 references in 5 years constantly. 
Table 2:

Self-cited and self-citing ratios of some highly cited journals ${ }^{* 1}$

rank journal

1. J. Am. Chem. SO..

2. Phys. Rev.

3. J. BioL Chem.

4 Nature

5. J. Chem. Sot.

6. J. Chem. Phys

7. Science

8. Biochim. Biophys. Acts

9. P. Nat, Acad. Sci. USA

10. Biochem. J.

11. Lancet

12. Phys. Rev, Letters

13. Comptes Rendus etc.

14. Amer. J. PhysioL

15. J. Org. Chem.

16. J. App[, Phys.

17. P. Sot. Exp. Biol. Med.

18. J. Mol. Biol.

19. J. Physiology (London)

20. P. Roy. Soc. London

average

501 Corrosion

502 IEEE T. Microwave Theory

503 Internat. J, Cancer

504 J. Nucl. Med.

505 Immunochemistry

506 IEEE T, Circ. Theory

507 J. Embryol. Exp. M\&phoL

508 Mutation Res.

509 Rev. Neurologique

510 IEEE T. Inform. Theory

511 LimnoL Oceanogr,

512 T. Brit. Mycol. Sot.

513 Psychopharmacologic

514 J. Microscopic (Paris)

515 Strahlentherapie

516 Aerospace Med.

517 Earth Planet. Sci. Lett,

518 P. Japanese Acad.

519 Amer. Psychologist

520 Amer. Zoologist

average

\begin{tabular}{|c|c|c|c|c|c|c|}
\hline times cited & $\begin{array}{l}\text { times } \\
\text { citing }\end{array}$ & $\begin{array}{l}\text { self } \\
\text { citation }\end{array}$ & $\begin{array}{l}\% \text { self- } \\
\text { cited }\end{array}$ & $\begin{array}{l}\% \text { self- } \\
\text { citing }\end{array}$ & citing/cited & \\
\hline 26307 & 10135 & 3503 & 13,3 & 34,6 & 0,4 & 5,859 \\
\hline 20666 & 14496 & 4452 & 21,5 & 30,7 & 0,7 & 3,679 \\
\hline 17103 & 8659 & 2052 & 12,0 & 23,7 & 0,5 & 6,371 \\
\hline 15310 & 6777 & 888 & 5,8 & 13,1 & 0,4 & 2,244 \\
\hline 13978 & 12230 & 2920 & 20,9 & 23,9 & 0,9 & 3,123 \\
\hline 13687 & 10710 & 3599 & 26,3 & 33,6 & 0,8 & 3,180 \\
\hline 9739 & 5699 & 528 & 5,4 & 9,3 & 0,6 & 2,894 \\
\hline 9500 & 10269 & 1347 & 14,2 & 13,1 & 1,1 & 3,287 \\
\hline 8206 & 4257 & 547 & 6,7 & 12,9 & 0,5 & 8,828 \\
\hline 7625 & 5220 & 848 & 11,1 & 16,3 & 0,7 & 3,193 \\
\hline 7612 & 4409 & 884 & 11,6 & 20,1 & 0,6 & 1,509 \\
\hline 6544 & 3230 & 608 & 9,3 & 18,8 & 0,5 & 5,114 \\
\hline 5642 & 8398 & 1349 & 23,9 & 16,1 & 1,5 & 0,780 \\
\hline 5417 & 3783 & 598 & 11,0 & 15,8 & 0,7 & 3,379 \\
\hline 5394 & 6848 & 1045 & 19,4 & 15,3 & 1,3 & 2,407 \\
\hline 5274 & 5811 & 848 & 16,1 & 14,6 & 1,1 & 1,936 \\
\hline 5011 & 4901 & 371 & 7,4 & 7,6 & 1,0 & 1,964 \\
\hline 4978 & 2486 & 620 & 12,5 & 24,9 & 0,5 & 9,302 \\
\hline 4960 & 2576 & 714 & 14,4 & 27,7 & 0,5 & 2,608 \\
\hline 4789 & 1746 & 103 & 2,2 & 5,9 & 0,4 & 3,484 \\
\hline & & & 13,3 & 18,9 & 0,7 & 3,8 \\
\hline 276 & 259 & 43 & 15,6 & 16,6 & 0,9 & 1,473 \\
\hline 273 & 697 & 138 & 50,6 & 19,8 & 2,6 & 1,242 \\
\hline 272 & 301 & 31 & 11,4 & 0,3 & 1,1 & 2,553 \\
\hline 268 & 309 & 44 & 16,4 & 14,2 & 1,2 & 0,505 \\
\hline 265 & 417 & 26 & 9,8 & 6,3 & 1,6 & 3,639 \\
\hline 265 & 381 & 91 & 34,3 & 23,9 & 1,4 & 1,344 \\
\hline 264 & 593 & 50 & 18,9 & 8,4 & 2,3 & 1,237 \\
\hline 264 & 935 & 92 & 34,9 & 9,8 & 3,6 & 2,607 \\
\hline 264 & 459 & 59 & 22,4 & 12,9 & 1,7 & 0,441 \\
\hline 263 & 483 & 95 & 36,1 & 19,7 & 1,8 & 0,946 \\
\hline 263 & 320 & 54 & 20,5 & 16,9 & 1,2 & 1,285 \\
\hline 263 & 549 & 73 & 27,8 & 13,3 & 2,1 & 0,830 \\
\hline 260 & 435 & 37 & 14,2 & 8,5 & 1,7 & 2,409 \\
\hline 261 & 559 & 31 & 11,9 & 5,6 & 2,1 & 0,986 \\
\hline 259 & 970 & 132 & 51,0 & 13,6 & 3,8 & 0,464 \\
\hline 257 & 1030 & 101 & 39,3 & 9,8 & 4,0 & 0,551 \\
\hline 257 & 892 & 63 & 24,5 & 7,1 & 3,5 & 2,262 \\
\hline 257 & 430 & 65 & 25,3 & 15,1 & 1,7 & 0,517 \\
\hline 254 & 395 & 38 & 15,0 & 9,6 & 1,6 & 0,331 \\
\hline \multirow[t]{2}{*}{249} & 848 & 29 & 11,7 & 3,4 & 3,4 & 0,326 \\
\hline & & & 24,6 & 11,7 & 2,2 & 1,3 \\
\hline
\end{tabular}

\footnotetext{
1 *Source: Garfield, E. (1974-76). Journal Citation Studies. XVII. Journal Self-Citation Rates - There's a Difference. Essays of an Information Scientist, Vol:2, p.192-194, 1974-76.
} 
Based on the table 2, Garfield in this essay found out that, most leading journals have a smaller self-cited than self-citing ratio. From the SCI core journals with the highest citations in 1969 we can see, that journal self citing has, as an average, a ratio of $19 \%$ for the first 20 journals. This value is going down for journals ranked later on to $12 \%$.

If this problem to be considered more precisely, it will show that there is a great variety of the self citing ratios from zero to one (Fig.2), and that the comparison of two similar samples from 2000 --- and 2005 ooo shows similar distributions.

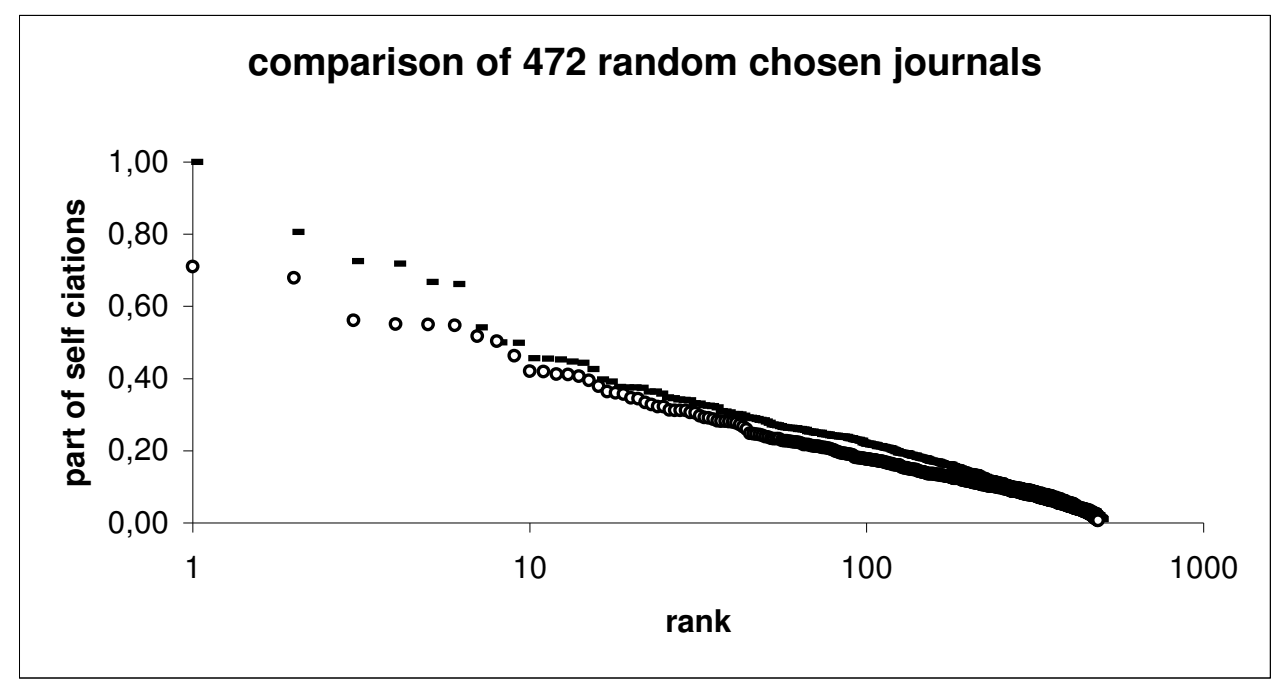

Fig.2: comparison self-citation rate among 472 random chosen journals in the JCR 2000 and the same set of journals in 2005

As the Fig. 2 shows, the portion of journal self citation is in 2000 (o) roughly $3 \%$ lower than in $2005(-)$.

Since many years, in most cases a journal is first on the list of journals, ranked by Journal Citation Reports (JCR) that it cites most frequently. 


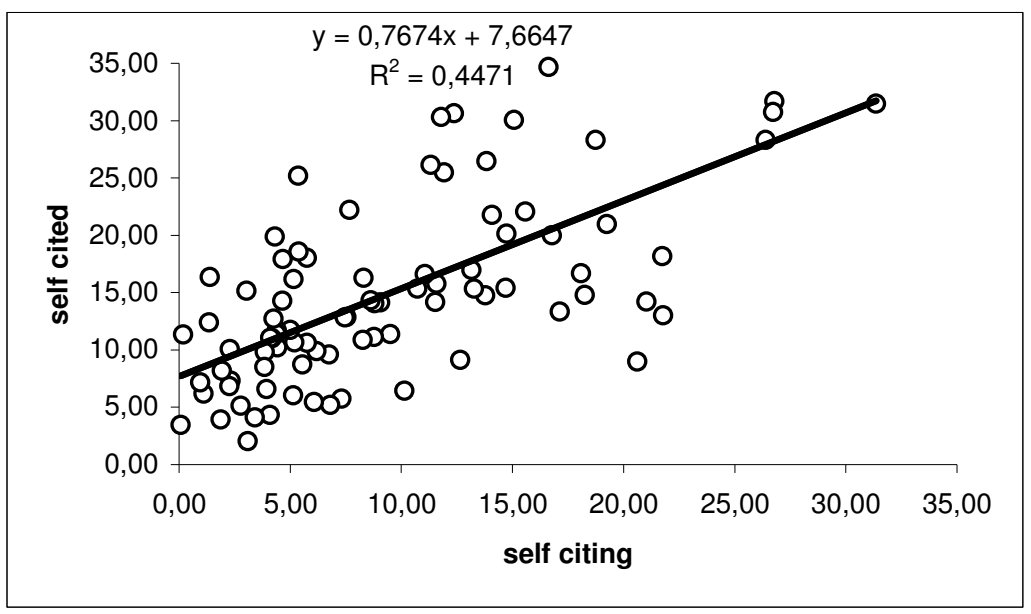

Fig.3: journal self citing and journal self cited values for 87 journals from JCR $*^{2}$

The graph (Fig.3) shows the relation of journal self-citing to self-cited data from M. Tsay for a sample of 87 journals. It indicates, that the mean self-cited rate is $5.4 \%$ greater than the mean self-citing rate (The mean self-citing rate is $9.59 \%$ and the mean self-cited rate is $15.03 \%)$.

The correlation of citing and cited values is clearly a function of the number of papers per journal. As more papers are published in a journal as more reference it has and as more often it will be cited. Fig.4, 5 and 6). This phenomenon is what Robert K. Merton called it, the Matthew Effect, which interpreted as "the rich get richer and the poor get poorer".

Using the data from table 2, we see a rather clear correlation between the number of citations of one journal and the number that this journal is cited by other sources.

\footnotetext{
2 *Source: Tsay, M: Journal self-citation study for semiconductor literature: Synchronous and diachronous approach Information Processing and Management 42 (2006) 1567-1577
} 


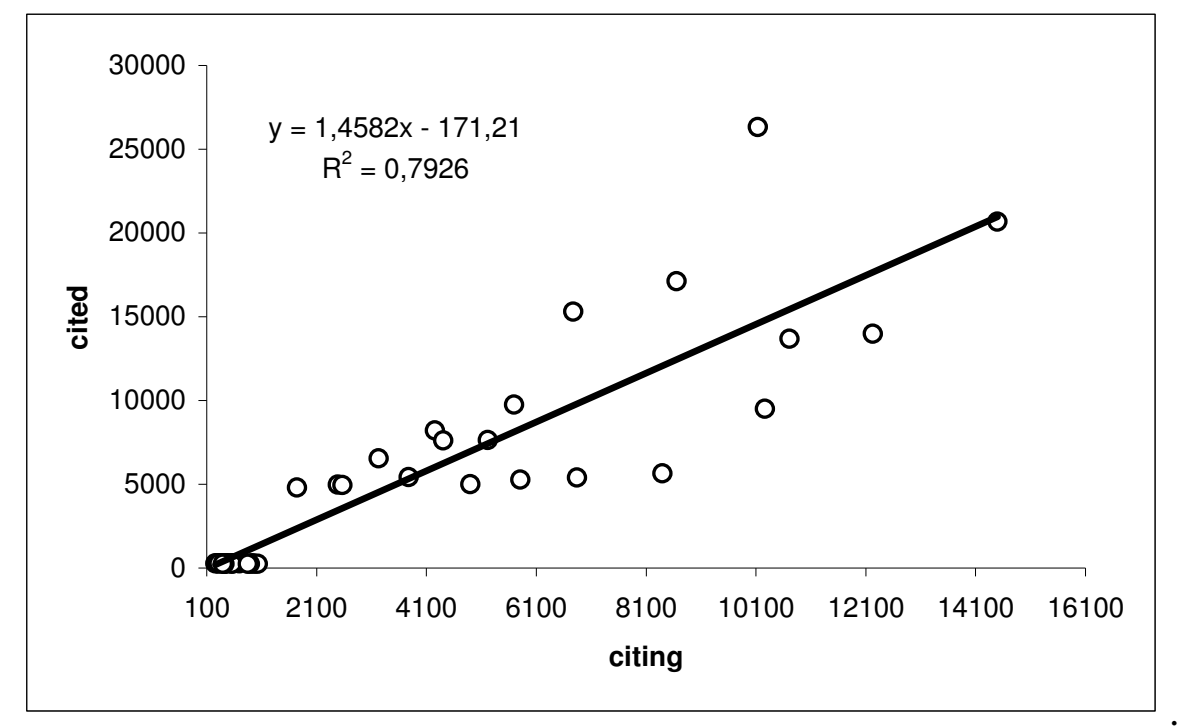

Fig.4: Comparison of the data from the columns "times cited" and "times citing" from table 2.

As the graph (Fig.4) shows there is a linear correlation between the frequency of citing and cited times. As often a journal is citing other journals as more often it is also cited by others with a factor of 1.5. In consequence the growing percentage of journal self citation is followed by journal self citedness (Fig.5a and 5b).

a.
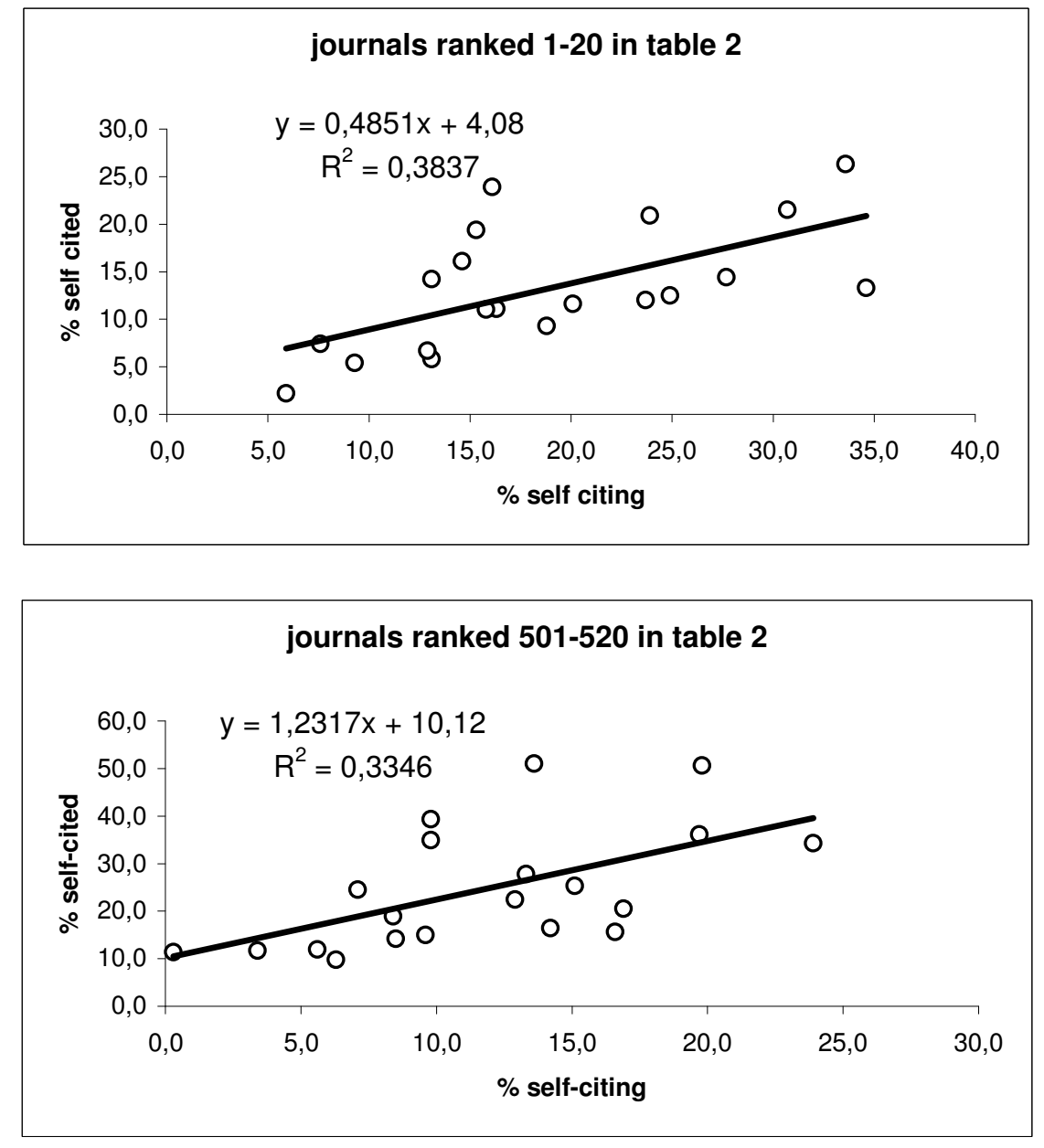
Fig.5: Comparison of the journal self citation data from the columns "\% self-cited" and "\% self-citing" in table 2.

The linear regression functions in Fig.5a and Fig.5b show that the value from Tsay $(0,767)$ is in the middle of Garfield's values $(0,485$ an 1,232).

$\mathrm{y}=0,7674 \mathrm{x}+7,66 \quad \mathrm{R}^{2}=0,45$ (from M. Tsay, 2001)

$\mathrm{y}=0,4851 \mathrm{x}+4,08 \quad \mathrm{R}^{2}=0,38$ (from E. Garfield 20 first ranked journals)

$y=1,2317 x+10,12 \quad R^{2}=0,38$ (from E. Garfield journals ranked 501-520)

Comparison of the journal self citation data from the columns "\% self-cited" and "\% selfciting" in table 2 makes clear that journals with high citation rates (Fig.5a) have a lower selfcitedness and (Fig.5b) vice versa. The results from Tsay have to be considered as an average.

The distribution of self citation follow roughly a log-normal distribution, so that we have to distinguish between the mean value of roughly $15 \%$ journal self citing and the mode of roughly $10 \%$. That means also, that the journals in the SCI got some more citations per paper and also higher IFs by journal self citation.

If we assume, that only $10 \%$ of the references are journal self citations, and if we compare these values with the increase of two thousand IFs in the years 2002 to 2004, then we see a clear parallel development. With other words, the raising IF in the SCI is produced by the growing number of references per paper and the nearly constant journal self citation rate.

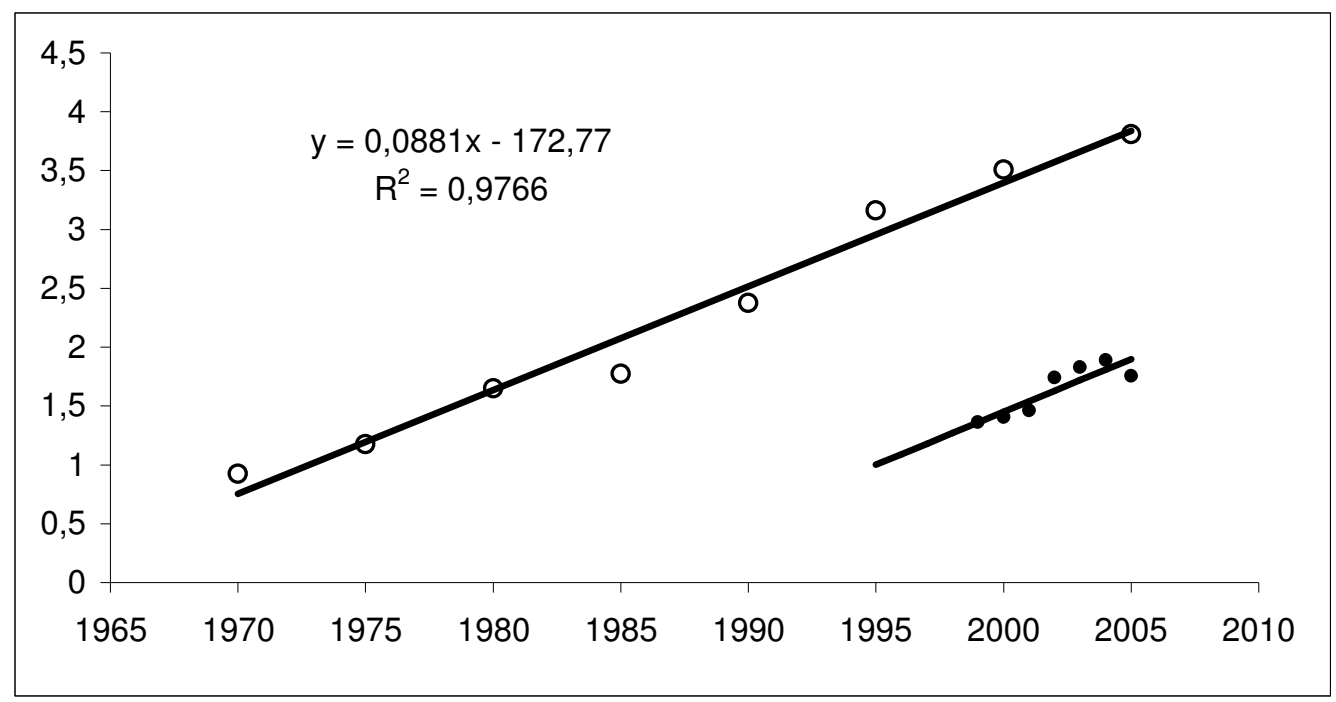

Fig.6: The parallel increase of IF (black points) by the raise of references per paper and the increase of citations to the same journal 
The graph (Fig.6) shows, the parallel increase of IF (black points) by the raise of references per paper and the increase of citations to the same journal.

The great differences in journal self citation rates from zero to one has different causes.

One can be identified in the specialization of the journals e.g. pomology, urban entomology or leather chemistry are without any doubt very special topics. This is a hint, that some of the journals with very special topics are much more concentrated to few journals than more interdisciplinary topics. Such differences are well known since the classical observations of Bradford in 1948.

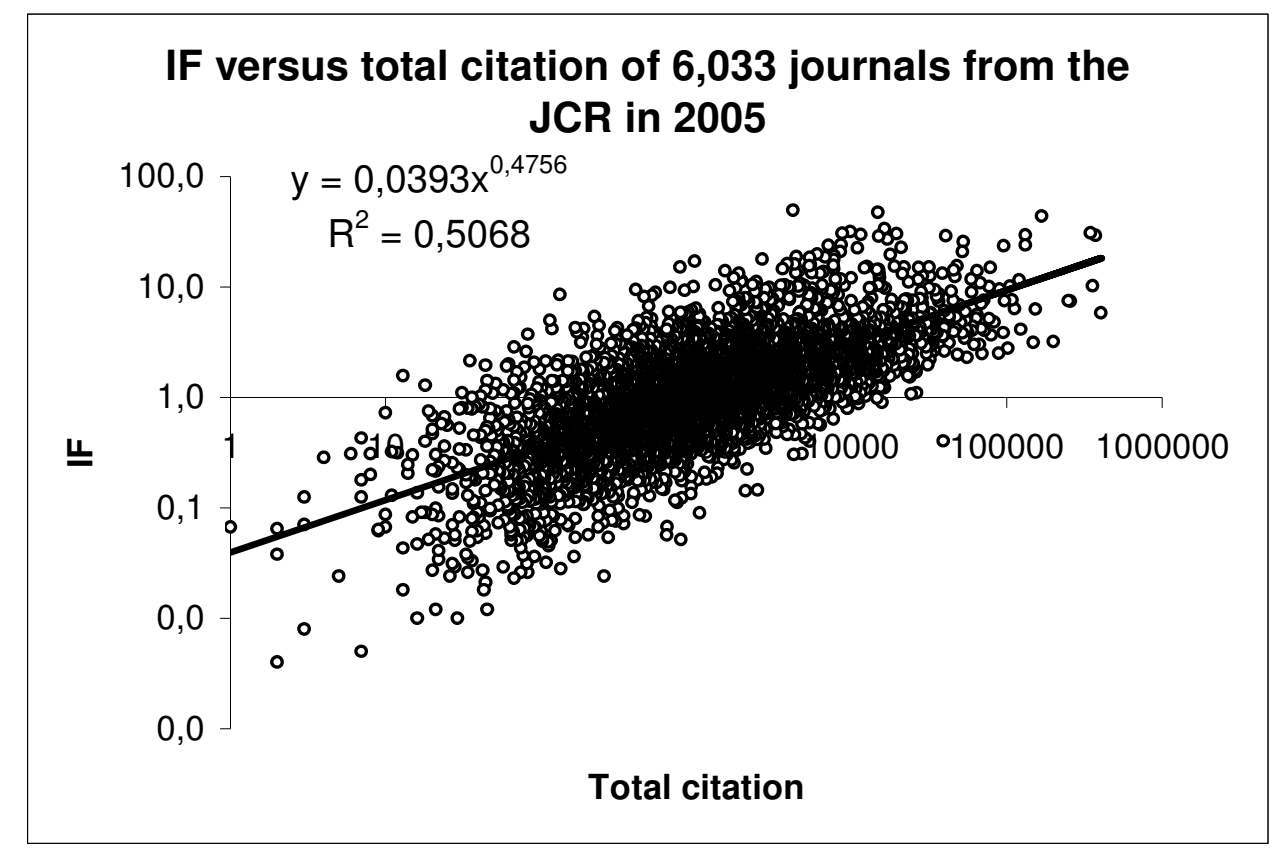

Fig.7: Impact Factors versus total citations for 6,033 journals from the JCR in 2005

As the graph (Fig.7) illustrates, there is a potential correlation (power law correlation) with a correlation coefficient $\mathrm{R}=0,71$ between the Impact Factors and the total citations of journals. The majority of journals with citations higher then 1,000 belong to the journals with IF $>1$.

The graph indicates that, there is a strong correlation between total citation and Impact Factors. $38.28 \%$ of total citation belong to the $5.8 \%$ of Journals with Impact Factor higher than 4 . And $61.72 \%$ of total citation belongs to the $94.20 \%$ of journals with IF lower than 4 . There is also an important hidden correlation between the IF and self-citation of journals, the 
self-citation rate of journals has parallel increased with the total-citation rate and consequently caused to increase the journals Impact Factors.

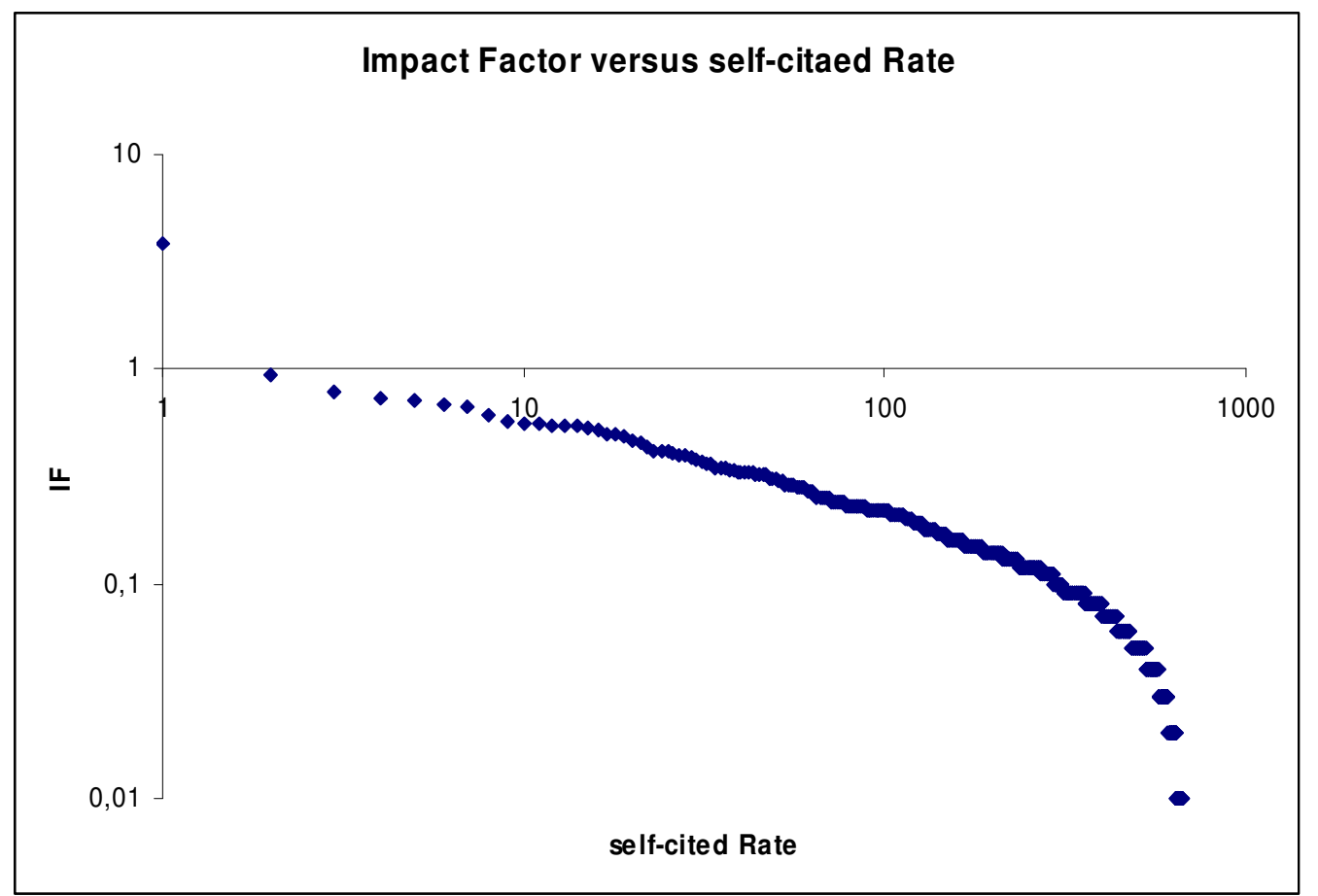

Fig.8: Impact Factor versus self-cited rate

As the graph (Fig.8) shows the self-citation rate has a negative correlation with IF. With lower IFs the self-citation rate is higher. In other words the journals with lower IF tend to be cited more by themselves. Most probable they have very special topics. 


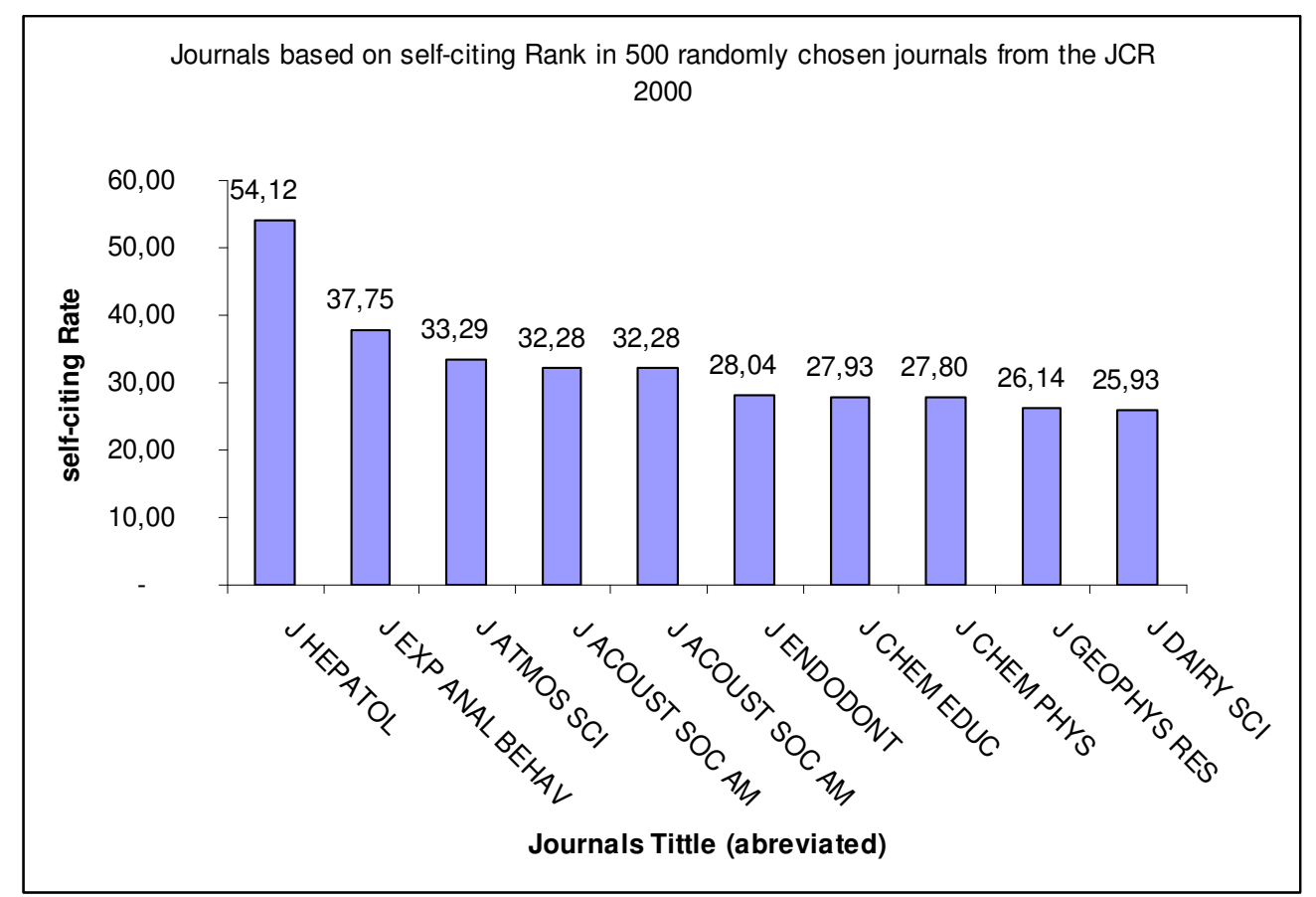

Fig.9: Distribution of journals based on self-citing rank for 500 randomly chosen journals from the JCR in 2000

The journals are ranked according to the adjusted self-citing rank. As the graph 9 illustrates, the Journal of "Hepatology" with $54.12 \%$ self-citing rate is the top self-citing journal followed by the Journal of the "Experimental Analysis of Behaviours" with 37.75\% self-citing rate. The graph restricted to the 10 top self-citing journals. 


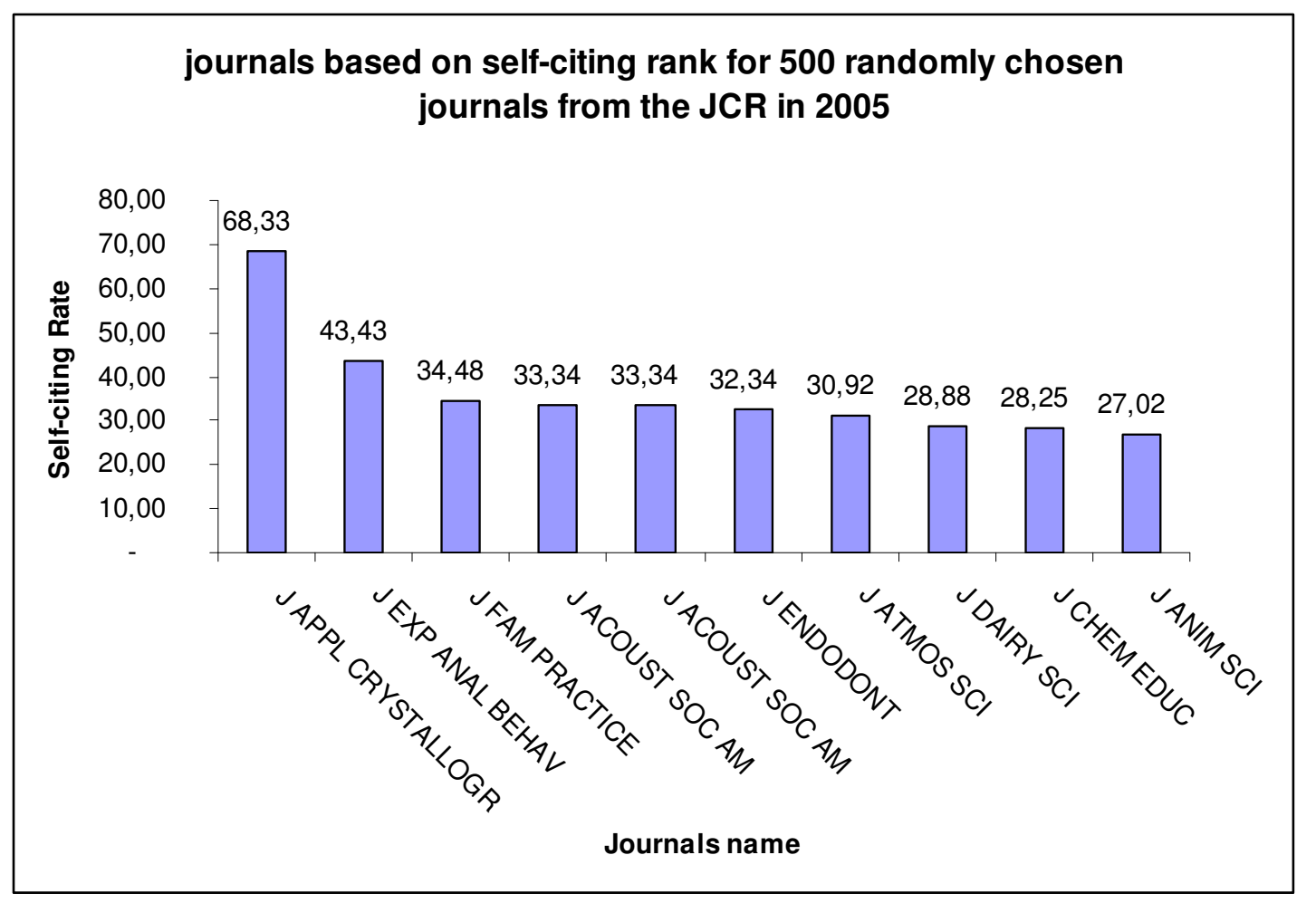

Fig.10: Distribution of journals based on self-citing rank for 500 randomly chosen journals from the JCR in 2005

As the graph 10 illustrates, the Journal of "Applied Crystallography" with $68.33 \%$ self-citing rate is the top self-citing journal followed by the Journal of the "Experimental Analysis of Behaviours" with $43.43 \%$ self-citing rate.

The graph restricted to the 10 top self-citing journals. 


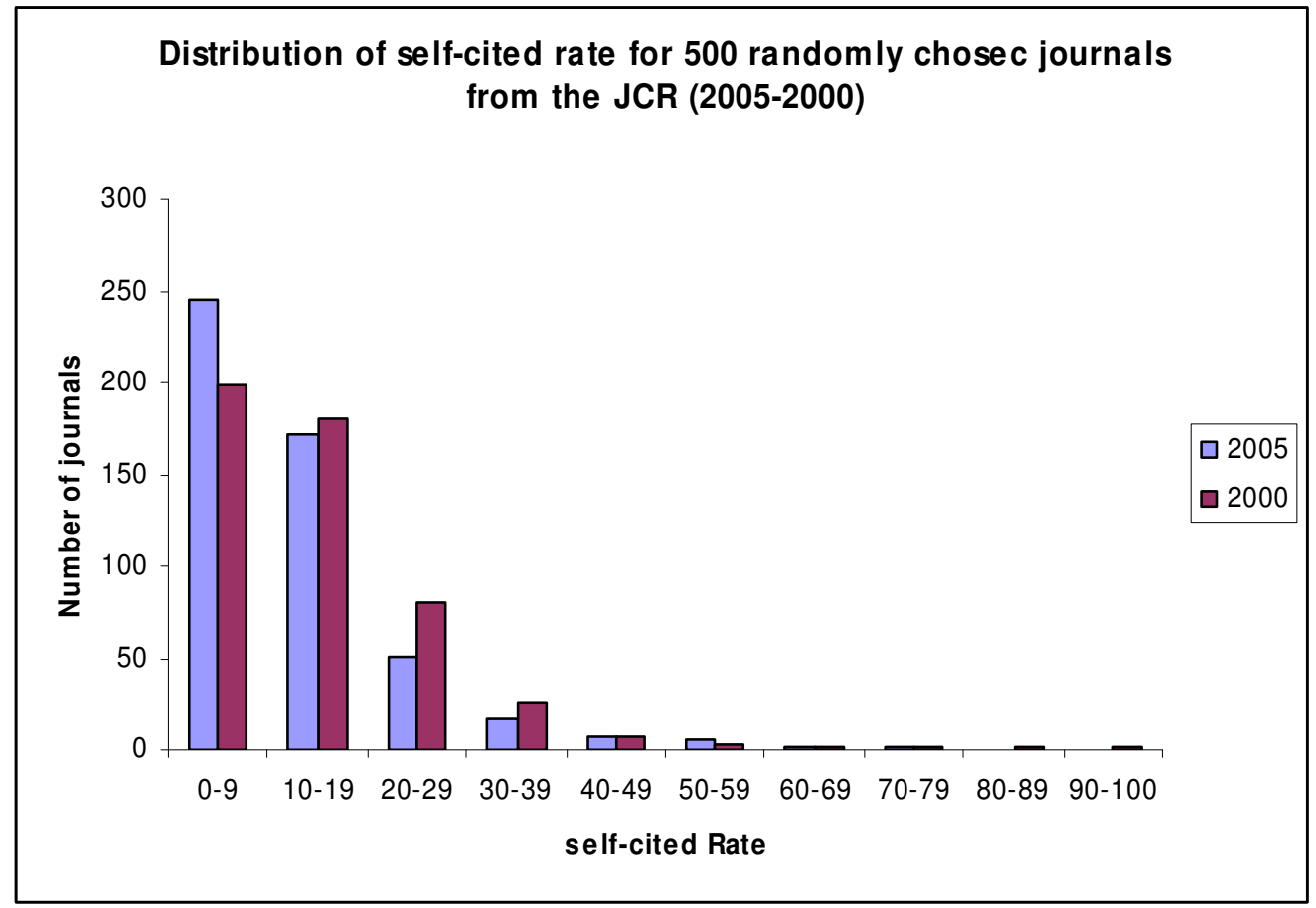

Fig.11: Histogram of Self-Citation Rates for the 5000 randomly chosen journals in the JCR (2005-2000)

As the graph (Fig.11) indicates, 422 journals (84.4\%) from a total of 500 randomly chosen journals in the JCR in 2005, has self-citations rates at or below 20 percent. The population shows a mean self-citation rate equal to 12 with a median of 10 in 2005 . This is very similar to the finding of Marie E. McVeig (7) that found $82 \%$ of all journals in the JCR in 2002 had self-citation rates at or below 20 percent with a mean self-citation rate equal to 12.41 and median of 9.04 .

As the graph 11 maps, the largest group in the self-cited group is that with the least self-cited rate less than $10 \%$ which account for 245 journals (49\%) from a total of 500 randomly chosen journals in 2005 and 198 journals (39.6\%) in 2000.

The second large group is the journals with a cited-rat from $10 \%$ to $20 \%$ in 2005 as well as in 2000 which constitute $34.4 \%$ of all journals in 2005 and $36 \%$ in 2000 . The mean value of self-citation rate is 14.81 with a median 12 for 500 randomly chosen journals in 2000 .

From a total of all 500 randomly chosen journals, $97.4 \%$ of all population in 2000, and $97.2 \%$ in 2005 had at least one citation to their own. 


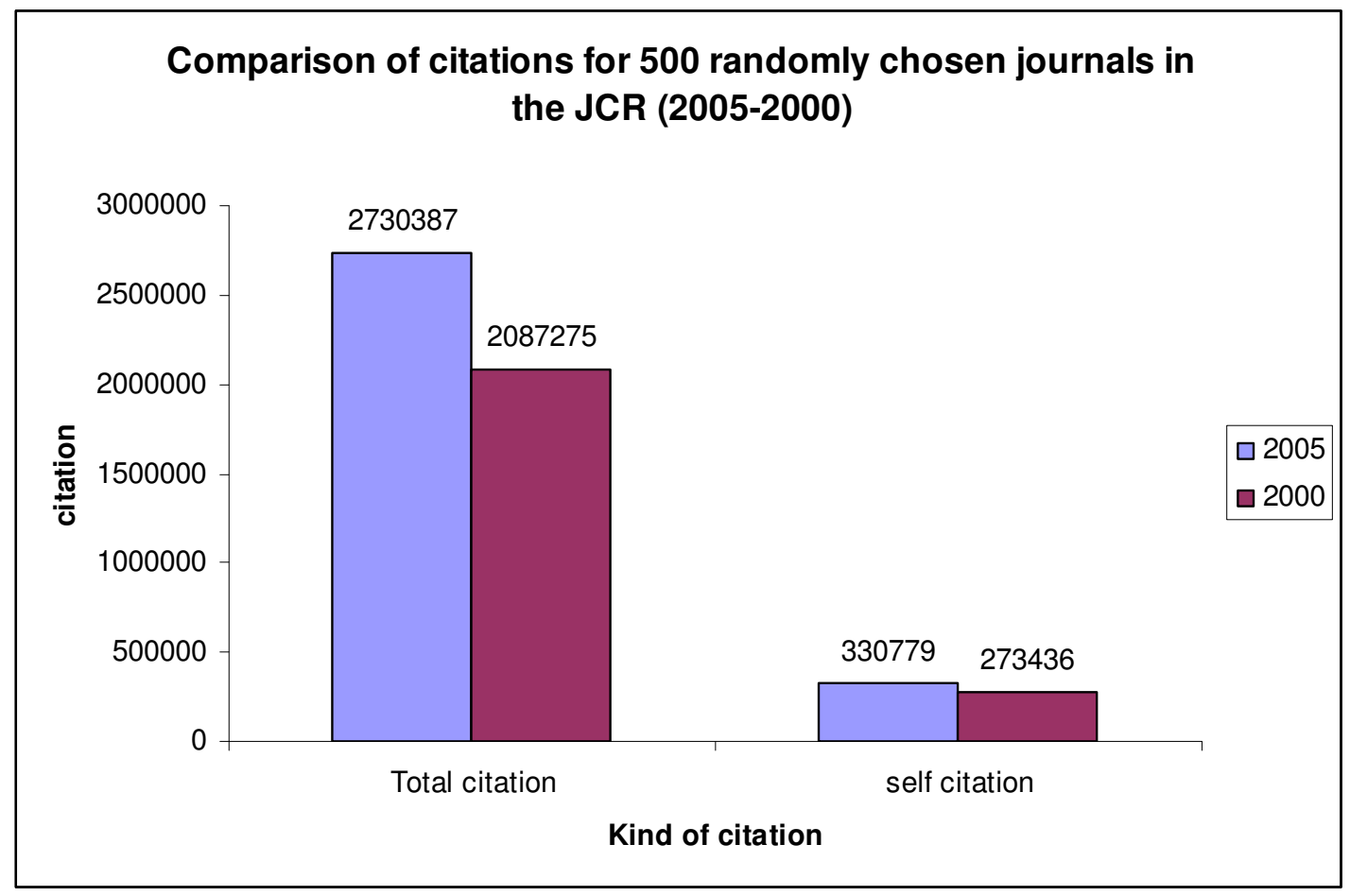

Fig.12: Comparison of citation and self-citation in 500 randomly chosen journals in the JCR $(2005-2000)$

The graph (Fig.12) illustrates the growth of citations and self-citation in 500 randomly chosen Journals in the JCR in the years2000 as well as in 2005 in the same set of journals.

Although the portion of self-citation over the span of the years stays approximately between $10-15 \%$ constant, but with considering that the number of total citation increased steady over the time, then the constant portion of self-citation has increased parallel with the total citation. For example total citation for 500 randomly chosen journals in the JCR in 2000 is 2,087,275 citations and the portion of self-citation is 273,436 (13.10\% of total citations in this year). The total citation in 2005 for the same set of journals is 2,730,387 citations, and the portion of self-citation in this year is 330,779 (12.11\% of all total citation).

It is clear that the $12.11 \%$ self-citation ratio in the year 2005 is 57,343 citations more that the $13.10 \%$ of self-citation ratio in the year 2000. It is clear that by this way the self-citation of journals causes to increase the total number of citations steady, consequently it cooperates to increase the Impact Factor of journals. This phenomenon is an important exploration what was not emphasised by other similar studies.

Table 3:

Mean value of journals self-citation rate for 3 groups of journals in the JCR 2005 


\begin{tabular}{|l|l|l|l|l|l|l|l|}
\hline Groups & $\begin{array}{l}\text { No. of } \\
\text { selected } \\
\text { journals }\end{array}$ & $\begin{array}{l}\text { Percent of } \\
\text { selected } \\
\text { journals in } \\
\text { the JCR }\end{array}$ & $\begin{array}{l}\text { Mean } \\
\text { value of } \\
\text { self- } \\
\text { citation } \\
\text { rate }\end{array}$ & $\begin{array}{l}\text { No. of total- } \\
\text { citations }\end{array}$ & $\begin{array}{l}\text { No. of } \\
\text { self- } \\
\text { citations }\end{array}$ & $\begin{array}{l}\text { Mean value } \\
\text { of total- } \\
\text { citation per } \\
\text { journal }\end{array}$ & $\begin{array}{l}\text { Mean } \\
\text { value of } \\
\text { self- } \\
\text { citation } \\
\text { per } \\
\text { journal }\end{array}$ \\
\hline IF $>9.846$ & 100 & $1.64 \%$ & $2 \%$ & $3,255,988$ & 75,497 & $32,559.88$ & 754.97 \\
\hline $4.352<\mathrm{IF}>5$ & 100 & $1.64 \%$ & $6 \%$ & $1,085,570$ & 101,486 & 10855.70 & 1014.86 \\
\hline $\mathrm{IF}<0.052$ & 100 & $1.64 \%$ & $17 \%$ & 10,613 & 1,999 & 106.13 & 19.99 \\
\hline
\end{tabular}

From all 6,088 number of journals indexed in the JCR in 2005 ascent sorted based on the IF, a total number of 100 journals with highest IF (IF>9.847), 100 journals with middle IF $(4.352<$ IF $>5$ ), and 100 journals with lowest IF (IF<0.052) were chosen in order to compare the totalcitation and self-citation behaviours in the JCR.

As the Table 3 indicates, the mean value of self-citation rate among journals with highest IF is $2 \%$ and this rate among the journals with lowest IF is $17 \%$, in other words the self-citation rate among the journals with lowest IFs in the JCR is more than 8 times higher than the selfcitation rate of journals with highest IFs.

Although the self-citation rate among the journals with highest IFs is 8.5 times lower than the self-citation rate among the journals with lowest IFs, but it should be considered that, the mean value of total citation per journal among journals with highest IFs is 307 time higher than the mean value of total-citation per journal among the journal with lowest IFs. And the mean value of self-citation per journals among the first group (the journals with highest IFs) is 38 times higher than the later group (the journals with lowest IFs 


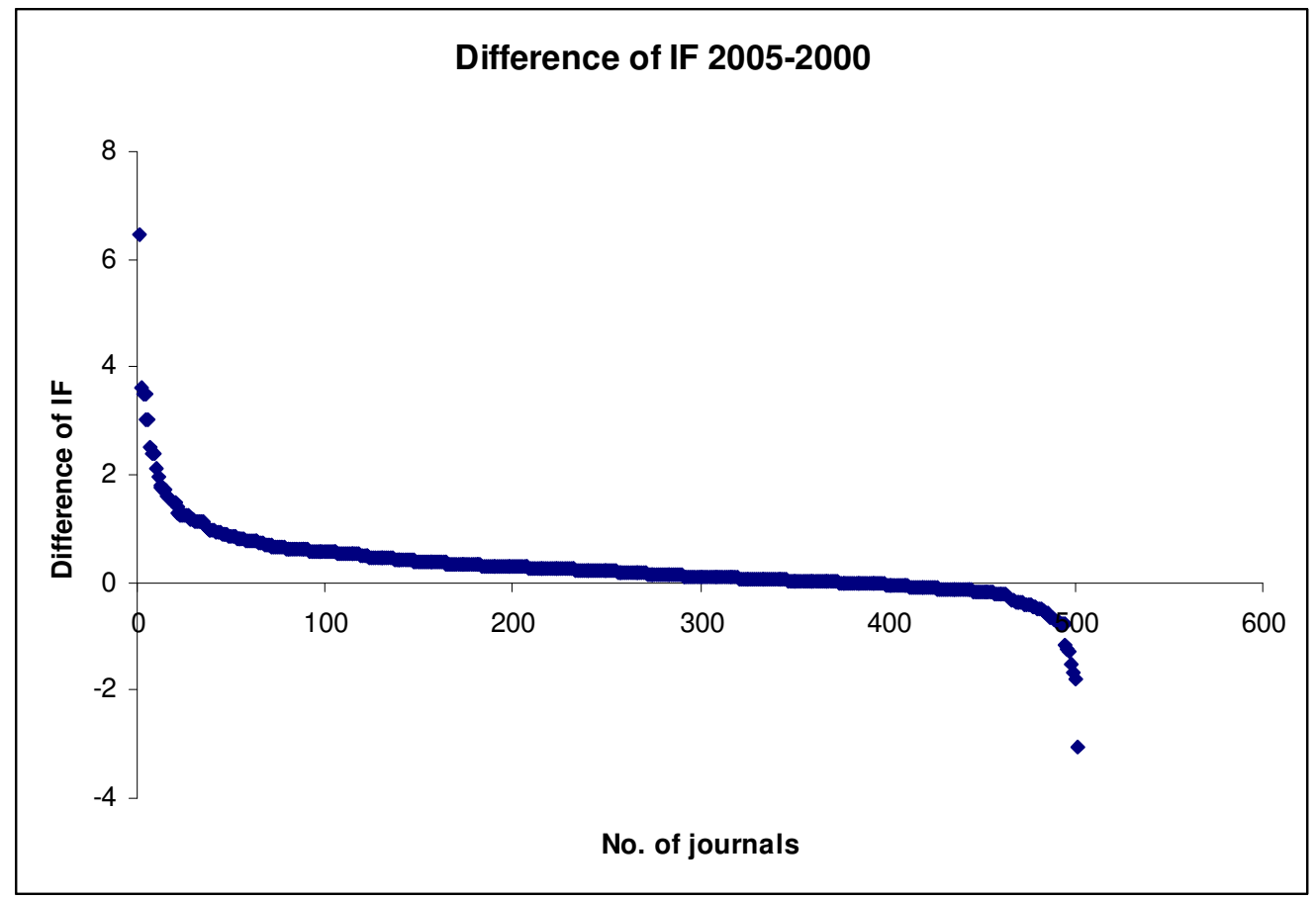

Fig.13: Difference of Impact Factors for 500 randomly chosen journals in the JCR (2000 2005)

The graph 13 shows the difference of IF for 500 randomly chosen journal from the JCR in 2002 and the same set of journals in 2005. As the graph illustrates the Impact Factor of $75 \%$ of Journals in 2005 is higher than the IF of the same set of journals in 2000. The Journal of Cell Biology showed dramatic decrease in the term of Impact Factor (its IF decreased from 13.995 in 2000 to 10.95 in 2005) and the Journal of ACM Computing Surveys Showed large increasing in the term of IF (it's IF increased from 0.923 in 2000 to 7.400 in 2005). 


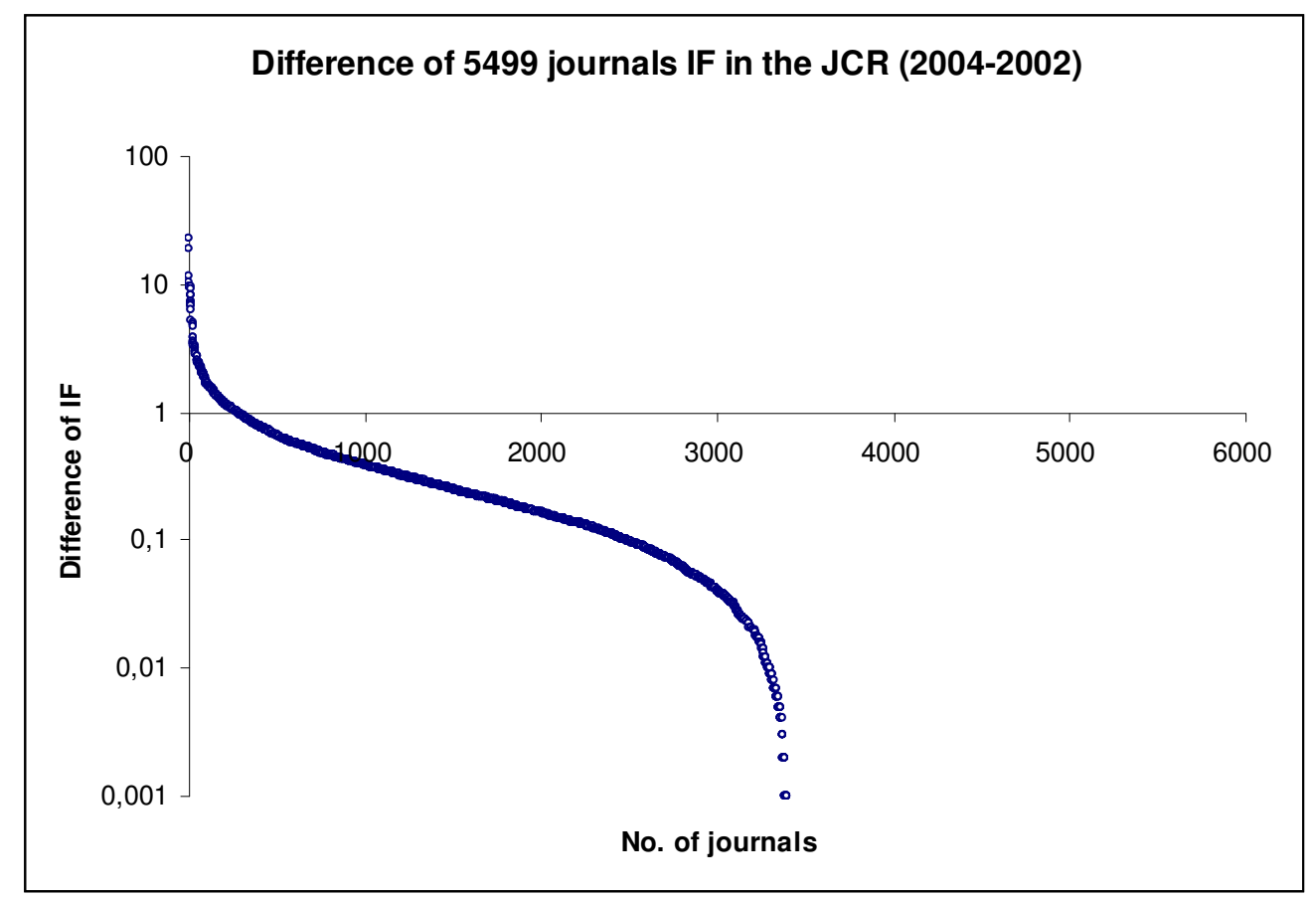

Fig.14: Difference of Journals Impact Factor for 5,499 journals in the JCR in 2004 and the same set of journals in 2002 .

As the graph (Fig.14) indicates, 61.81\% of all journals IF in 2004 indexed in the CJR with compare to the same set of journals in 2002 has increased, $0.42 \%$ stayed unchanged, and $37.77 \%$ has sunk.

\section{Conclusion:}

Analysis of data showed that the number of references per paper from 1970 to 2005 has steady increased. It reached from 8.40 in 1970 to 34.63 in 2005 , an increase of more than 4 times.

The most majority of publications $(76.17 \%)$ are in the form of Journals article, after articles, Meeting abstract with $9.46 \%$, Note with $3.90 \%$ and Editorial material with $3.78 \%$ are respectively the most frequented publication forms.

94.57\% of all publications are in English. After English German with 1.50\%, Russian with $1.48 \%$ and French with $1.37 \%$ are respectively the most frequented languages.

Comparison of journals Impact Factor for 5,499 journals in 2002 in the JCR and the same set of journals in 2005(Fig.11) indicates that $61 \%$ of journals IFs have increased over the span of the years in the same set of journals. 
Analysis of data showed that there is a significant correlation between the IF and total citation of journals in the JCR, and there is an important hidden correlation between IF and the selfcitation of journals. The study showed that the IF of journals has increased parallel by the raise of references per paper and the increase of citations to the same journals through out 1999-2005 (Fig.6).

We found that there is a linear correlation between journal self-citing and journal self-cited value, the mean value of self-cited rate always stays higher than the self-citing rate.

The mean value of self-cited rate in 2000 is $14 \%$ and the mean value of self-citing rate is $6.61 \%$, whereas the mean value of self-cited rate in 2005 is $12 \%$ and the mean value of selfciting rate is $7.81 \%$.

Analysis of data showed that as more often a journal is citing other journal as more often it is also cited by a factor of 1.5 from others. In consequence the growing percentage of journal self citation is followed by journal self citedness. This phenomenon is that the researchers call it, the Matthew Effect, which interpreted as "the rich get richer and the poor get poorer".

The other finding of study is that, although the portion of self-citation over the span of the years stays approximately between 10-15\% constant, but with considering that the number of total citation increased steady over the time, and then the constant portion of self-citation has increased parallel with the total citation. For example total citation for 500 randomly chosen journals in the JCR in 2000 is 2,087,275 citations and the portion of self-citation is 273,436 (13.10\% of total citations in this year). The total citation in 2005 for the same set of journals is $2,730,387$ citations, and the portion of self-citation in this year is 330,779 ( $12.11 \%$ of all total citation).

It is clear that the $12.11 \%$ self-citation ratio in the year 2005 is 57,343 citations more that the $13.10 \%$ of self-citation ratio in the year 2000 .

Comparison of the number of self-citation for 100 top journals with 100 low journals ranked based on the IF in 2005 showed that in spit of high self-citation rate among low ranked journals, the number of self-citation made by high ranked journals is 37.37 times higher. The total numbers of self-citation made by high ranked journals is 75,497 citations and the self-citation made by low ranked journals is 2020 citations. The self-citation rate by high ranked journals is $2 \%$ whereas by low ranked journals is $17 \%$.

\section{References:}

1. Fassoulaki A., Paraskeva A., Papilas K. and Karabinis G.(2000). Self-citations in six anaesthesia journals and their significance in determining the impact factor. $\mathrm{Br} \mathrm{J}$ Anaesth; 84:266-9.

2. Garfield, E.(1974-76). Journal Citation Studies, XVII, Journal Self-Citation Rates - There's a Difference. Essays of an Information Scientist, Vol: 2, p.192-194, 1974-76.

3. Garfield, E. (1979-80). Trends in biochemical literature, Essays of an Information Scientist, Vol. 4, p.419-425.

4. Garfield, E.(1980). The Number of Biochemical Articles Is Growing, But Why Also the Number of References per Article? Essays of an Information Scientist, Vol:4, p.414-418. 
5.Garfield E.(1979). How do we select journals for Current Contents, Current Contents 45, p.5-8.

7. .McVeigh, M.E.(2004). Journal self-citation in the Journal Citation Reports - Science edition (2002): A citation study from the Thomson Corporation. The Thomson Corporation. Retrieved October 25, 2006: from

http://www.thomsonscientific.com/media/presentrep/essayspdf/selfcitationsinjcr.pdf.

9. Robert K. Merton, The Matthew Effect in Science, The reward and communication systems of science are considered, Science, 159(3810): 56-63, January 5, 1968. Retrieved October 25, 2006 from: http://www.garfield.library.upenn.edu/merton/matthew1.pdf.

10. Ron Bryant. A Short Bibliometric Study: Personal Bibliometric Profile of AC De Vries;

Critical Analysis and Future Potential. Retrieved December 11, 2006 from

http://www.earth.sinica.edu.tw/libhome/e-j/Borgman.pdf.

11. Thomas E. Nisonger (2000). Use of the Journal Citation repose for Serials management in research Libraries: An Investigation of the Effect of self-citation on journals ranking in library and information science and genetics, College \& Research Libraries, v61 n3 p263-75.

Retrieved October 25, 2006 from:

http://www.ala.org/ala/acrl/acrlpubs/crljournal/backissues2000b/may00/nisonger.pdf.

12. Tsay, M. (2006). Journal self-citation study for semiconductor literature: Synchronous and diachronous approach Information Processing and Management, Vol:42, P.1567-1577. 